1. Small N. Theories of grief: a critical review. In: Hockey J, Katz J, Small N, editors. Grief, mourning and death ritual. Buckingham: Open University Press, 2001: 19-48.

2. Riches G, Dawson P. An intimate loneliness: supporting bereaved parents and siblings. Buckingham: Open University Press, 2000.

3. Walter T. On bereavement. Buckingham: Open University Press, 1999.

4. Walter T. Letting go and keeping hold: a reply to Stroebe. Mortality 1997; 2(3) 263-266.

5. Jalland P. Australian ways of death: a social and cultural history 1840-1918. Melbourne: Oxford University Press, 2002.

6. Parkes CM, Laungani P, Young B, editors. Death and bereavement across cultures. London: Routledge, 1997.
7. Raphael B. Grief and loss in Australian society. In: Kellehear A, editor. Death and dying in Australia. Melbourne: Oxford University Press, 2000: 116-129.

8. Klass D, Silverman PR, Nickman SL, editors. Continuing bonds: new understandings of grief. London: Taylor and Francis, 1996

9. Marwitt SJ, Klass D. Grief and the role of the inner representation of the deceased. Omega 1995; 30: 283-298.

10. Howarth G. Dismantling the boundaries between life and death. Mortality 2000; 5(2): 127-138

11. Bennett G, Bennett KM. The presence of the dead: an empirical study. Mortality 2000; 5(2): 139-157

\title{
Otitis media in Aboriginal children: tackling a major health problem
}

\section{Improved living conditions hold the key}

Chronic SUPPURATIVE OTITIS MEDIA (CSOM) (see Box) is very uncommon in First World countries and is best regarded as a disease of poverty. The World Health Organization has indicated that a prevalence rate of CSOM greater than $4 \%$ in a defined population of children is indicative of a massive public health problem requiring urgent attention. ${ }^{1}$ That CSOM affects up to ten times this proportion of children in many Aboriginal communities is an indictment of the poor living conditions in these communities. ${ }^{2}$ The associated hearing loss has a life-long impact, as it occurs during speech and language development and the early school years.

\section{Why is chronic suppurative otitis media so recalcitrant?}

Many factors contribute to poor health outcomes. In biological terms, the greatest risk factor for the early onset and persistence of otitis media is nasopharyngeal colonisation by multiple bacterial species and subtypes. ${ }^{3}$ In Aboriginal communities with overcrowded households, infants are frequently exposed to siblings whose nasopharyngeal carriage rates are almost $100 \%$ for each of the major otitis media bacterial pathogens. ${ }^{3}$ In non-Aboriginal children, the host response to a low-dose infection usually eradicates pathogens, which, in turn, down-regulates inflammation and limits tissue damage. In contrast, we believe that early exposure of very young Aboriginal infants to a large bacterial inoculum (or frequent exposures to immunologically distinct pathogens) ${ }^{4}$ provides constant stimulation of the inflammatory cascade, which damages mucosal tissue yet fails to eradicate pathogens. ${ }^{5}$ This begins a vicious cycle that may persist throughout childhood: early exposure, persistent bacterial colonisation, and chronic mucosal disease. Furthermore, such infants themselves become chronic carriers and pose a risk to other, younger infants. This cycle is facilitated by overcrowded and poor living conditions, lack of appropriate washing facilities, ${ }^{6}$ and limited access to appropriate healthcare services.

Bulging of the tympanic membrane is the best diagnostic predictor of perforation. ${ }^{7}$ Other signs and symptoms of acute otitis media (such as pain, fever, irritability or redness of the tympanic membrane) are frequently absent in this population. The implications of this lack of signs or symp-

\begin{abstract}
Otitis media - definitions
Acute otitis media without perforation: Presence of middle-ear fluid with symptoms or signs of suppurative infection. Bulging of the tympanic membrane is the most reliable sign in Aboriginal children.
\end{abstract}

Acute otitis media with perforation: Acute suppurative infection with recent discharge from the middle ear (within the last 7 days).

Otitis media with effusion: Presence of middle-ear fluid without symptoms or signs of suppurative infection.

Chronic suppurative otitis media: Persistent discharge from the middle ear through a tympanic membrane perforation for more than 6 weeks.

toms are clear - parents do not see their child as unwell and thus children remain untreated.

Together, this biological model and clinical pattern help us to understand the intractable nature of otitis media in Aboriginal children. Currently, failure to apply existing knowledge is a more important problem than lack of knowledge. Aboriginal children have poorer access to therapy, hearing aids, special teachers, classroom soundfield systems and other rehabilitative programs. ${ }^{2}$ Furthermore, there is inequitable distribution of funds from the Commonwealth Hearing Health Services Program, with evidence that the hearing health needs of Aboriginal children are not being met. $^{8}$

\section{What strategies have worked?}

A systematic review of existing evidence and primary care guidelines for the management of otitis media in Aboriginal and Torres Strait Islander people ${ }^{2}$ identified effective primary prevention strategies: improving nutrition and the home environment, increasing breastfeeding, and reducing passive smoking. A small but important role was noted for vaccines (the polysaccharide, polyvalent pneumococcal vaccine and the new pneumococcal conjugate vaccine). Controversies remain regarding the effectiveness of antibiotics in primary prevention and the impact of maternal pneumococcal vaccination on infant disease. ${ }^{2}$

High doses and prolonged courses of antibiotics are often required for the treatment of acute otitis media and $\mathrm{CSOM}^{7}{ }^{7}$ but the optimal use of topical ear preparations 
remains uncertain. ${ }^{2}$ Where appropriate primary healthcare interventions have failed, timely referral to otolaryngologists for assessment and surgical interventions can improve hearing outcomes. ${ }^{2}$ However, access to such specialist care for children in remote Aboriginal communities is suboptimal. Audiological rehabilitation is critical, requiring the provision of ongoing education about effective communication strategies and appropriate use of devices to assist hearing. These include standard hearing aids and bone conductors, as well as classroom devices such as soundfield amplification systems (which provide a uniform soundfield throughout the classroom and increase the speech-signal : noise ratio), and FM systems (a form of personal amplification whereby an FM signal from a microphone worn by the teacher is picked up by a receiver worn by a child with hearing loss). ${ }^{9}$

\section{What needs to happen in the future?}

Greater community control over improvements to education, employment opportunities, housing infrastructure and primary healthcare services is long overdue. To realise these improvements requires substantially increased resources, linked to community responsibility. In the meantime, initiatives that increase access to primary healthcare for the detection and management of ear disease and facilitate access to other services should continue. An example is the Office for Aboriginal and Torres Strait Islanders Health Hearing Health Program. ${ }^{10}$ Realistic expectations about the benefits and harms of evidence-based healthcare interventions should be incorporated into updates of currently available clinical guidelines, and the information made accessible to families. The Commonwealth needs to reform the provision of rehabilitative services and coordinate approaches to soundfield amplification in schools.

The research priority is to determine the best use of preventive strategies and interventions (including educational, medical, surgical and audiological initiatives). Multidisciplinary research in the areas of diagnosis, new antibiotics, the role of biofilm and vaccines is also appropriate. Bacterial biofilm is a community of interacting bacteria attached to a surface and encased in a protective matrix of

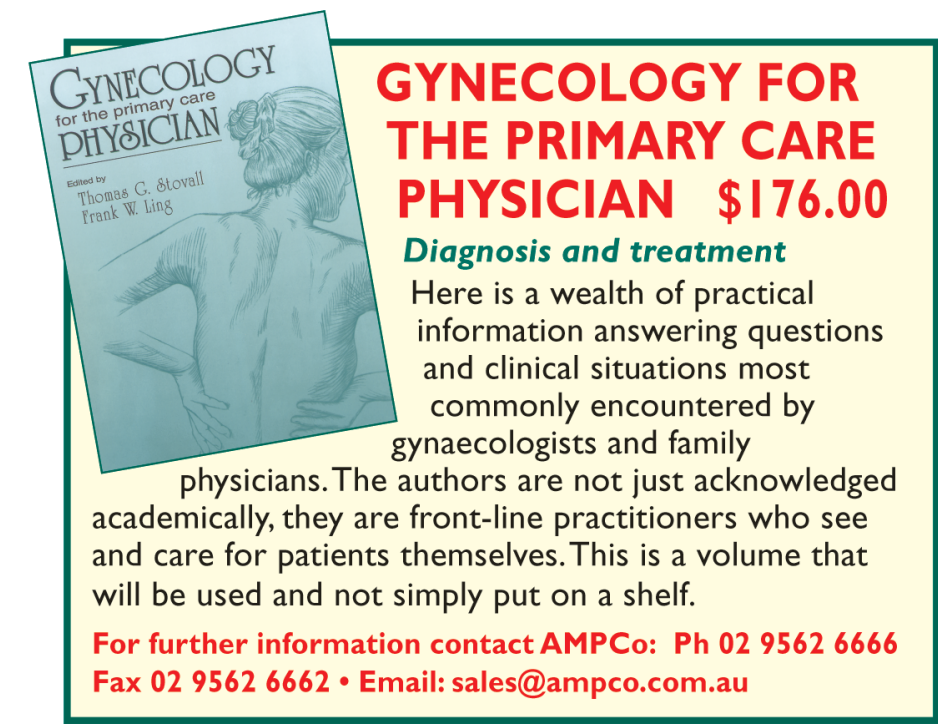

exopolysaccharide. Formation of biofilm in the middle-ear mucosa of Aboriginal children with CSOM may explain the recrudescence of bacterial otorrhoea after viral upper respiratory tract infections. ${ }^{11}$ Pneumococcal conjugate and innovative protein-based vaccines are aimed at inducing a mucosal immune response. Several Australian trials are currently examining the impact of pneumococcal conjugate vaccine on nasopharyngeal carriage rates and perforation of the tympanic membrane.

Only with urgent attention to improving housing and access to running water, nutrition and quality of care, and giving communities greater control over these improvements, will this massive public health problem be solved so that Aboriginal children can take their rightful place in this, the century of communication.

Harvey L Coates

Clinical Associate Professor; and Paediatric Otolaryngologist Department of Otolaryngology, Princess Margaret Hospital for Children Subiaco, WA

Peter S Morris

Head, Ear Health and Education Unit

Amanda J Leach

Senior Research Officer Menzies School of Health Research, Darwin, NT

Sophie Couzos

Public Health Officer National Aboriginal Community Controlled Health Organisation Canberra, ACT harveyc@cyllene.uwa.edu.au

Reprints: Clinical Associate Professor Harvey L Coates, Department of Otolaryngology, Princess Margaret Hospital for Children, Roberts Road, Subiaco, WA 6008

1. WHO/CIBA Foundation Workshop. Prevention of hearing impairment from chronic otitis media. WHO/PDH/98.4. 1996. London, CIBA Foundation. 19-111996.

2. Couzos S, Metcalf S, Murray R, of the National Aboriginal Community Controlled Health Organisation (NACCHO). Systematic review of existing evidence and primary care guidelines on the management of otitis media in Aboriginal and Torres Strait Islander populations. Canberra: Office for Aboriginal and Torres Strait Islander Health, 2001.

3. Leach A, Boswell J, Asche V, et al. Bacterial colonisation of the nasopharynx predicts very early onset and persistence of otitis media in Australian Aboriginal infants. Pediatr Infect Dis J 1994; 13 : 983-989.

4. Smith-Vaughan HC, McBroom J, Mathews JD. Modelling of endemic carriage of Haemophilus influenzae in Aboriginal infants in Northern Australia. FEMS Immunol Med Microbiol 2001; 31: 137-143.

5. Cole PJ. Inflammation: a two-edged sword - the model of bronchiectasis. Eur J Respir Dis Supp/ 1986; 147: 6-15.

6. Runcie M, Bailie R. Evaluation of environmental health survey data - Indigenous housing. Darwin, NT: The Cooperative Research Centre for Aboriginal and Tropical Health, 2000. ISBN 1876831189.

7. Morris $P$, Ballinger D, Leach $A$, et al. Recommendations for clinical care guidelines on the management of otitis media in Aboriginal and Torres Strait Islander populations. Canberra: Office of Aboriginal and Torres Strait Islander Health, 2001

8. National Aboriginal Community Controlled Health Organisation (NACCHO). Summary of the "Report on the delivery of hearing services to Aboriginal and Torres Strait Islander Peoples". Member of the Advisory Group for the Review of Hearing Services, delivered by the Commonwealth to Aboriginal and Torres Strait Islander People, 16 August 2001. Available at: http://www.naccho.org.au/HearingHealth.html (accessed 18 July 2002)

9. Aboriginal, Rural and Remote Interest Group for the Audiological Society of Australia. General guidelines for audiological practice with Indigenous Australians. Audiological Society of Australia, June 2001. Available at: http://www.audiology.asn.au/ (accessed 31 May 2002).

10. Government response to the House of Representatives Inquiry into Indigenous Health - "Health is Life" report. March 2001. Available at: http:// www.health.gov.au/oatsih/healthlife/index.htm (accessed 18 July 2002).

11. Post JC. Direct evidence of bacterial biofilms in otitis media. Laryngoscope 2001; 111: 2083-2094. 